\title{
O ESTATUTO DA CRIANÇA E DO ADOLESCENTE: rumo à maioridade
}

THE STATUTE OF CHILD AND ADOLESCENT: towards majority

Felipe Tonelli ${ }^{1}$

\begin{abstract}
Resumo
O presente artigo visa a contribuir para o debate crítico da Lei n. 8.069/1990, o Estatuto da Criança e do Adolescente. Reconhecemos que algumas adaptações normativas são necessárias, sem prejuízo das garantias fundamentais adquiridas, posto que tal lei é o resultado legítimo do processo democrático de inserção da República Federativa do Brasil no sistema internacional de proteção dos direitos humanos. Contudo, as reformas que se fizerem necessárias precisam ultrapassar o debate oportunista, e isso é o que nos adverte a revisão histórica da legislação infanto-juvenil.

Palavras-Chave: Estatuto da Criança e do Adolescente. Proteção Integral. Direitos Humanos. Maioridade Penal.
\end{abstract}

\begin{abstract}
The present article intends to contribute to the critical debate about the childhood legislation in Brazil, the called "Estatuto da Criança e do Adolescente" (Lei n. $8.069 / 1990)$. It purposes that the reduction of the criminal age of majority is not a exigent measure. Instead, claiming for adequate modifications, wich are proper to historical context like in Brazil, just recognizes the improvement of democratic instruments as happened after the Declaration of the Rights of the Child, in 1959.
\end{abstract}

Keywords: Childhood Legislation (Brazil). "Best Interests of the Child" Doctrine. Human Rights. Criminal Age of Majority.

1. Introdução: Crianças e Adolescentes em tempos de virada: à procura de um pai autoritário?

Historicamente, o Brasil adota a imputação penal apenas para os maiores de 18 anos após o Código Penal de 1940. Antes disso, vigente o Código Penal, de 1890, consideravam-se os limites de 9 aos 14 anos, sendo que até aos 9 anos o infrator era considerado inimputável e entre 9 e 14 o juiz verificava se o infrator havia agido com discernimento, podendo ser considerado criminoso (art. 27, $\S 1^{\circ}$ e $\S 2^{\circ}$ ). Se isso provoca espanto, vale dizer que a proteção social oferecida às crianças era conduzida à altura da política criminal do Código Penal. Em caso de abandono, as crianças eram entregues às

O Autor é graduando na Faculdade de Direito da Universidade de São Paulo. E-mail: tonelli_felipe@yahoo. com.br. 
Casas dos Expostos, instituições precárias que chegavam a registrar índices de mortalidade superior a 90\%, conforme relata Arthur Moncorvo Filho. ${ }^{2}$

O próprio nome de Arthur Moncorvo Filho é indispensável para analisar a alteração do rumo que se daria entre o fim do século XIX e o começo do século XX. Conforme estudo realizado por James E. Wadsworth, ${ }^{3}$ o pediatra foi um dos responsáveis pela implantação nacional, em 1924, do Dia da Criança (12 de outubro), tendo criado, em 1880, o Instituto de Proteção e Assistência à infância, no Rio de Janeiro.

$\mathrm{O}$ movimento de assistência à infância acabou por converter-se numa cruzada pessoal de Moncorvo Filho, que se engajou apaixonadamente na luta, tendo construído modelos institucionais e ideológicos com os quais esperava alterar o conteúdo e a forma do sistema assistencial, inclusive em associação com entidades internacionais. Tais modelos eugenistas, por ele propostos, fornecem uma perspectiva singular a respeito da criação do sistema de assistência à infância no Brasil, de modo a clarificar como os médicos, advogados e políticos do período perceberam a assistência à infância e que motivações tiveram para se envolverem nesta campanha.

Subjacente a esse processo - que só se aperfeiçoará com o Código de 1927 - cumpre esclarecer que a infância passou a gozar de reconhecimento legal somente após a abolição da escravidão. Em uma sociedade onde se intensificava a competição, a prosperidade do País passaria também pela legislação menorista. Por isso o cabimento de uma legislação especial, que haja a contento com os propósitos modernizadores apregoados no início do século passado, ainda que encabeçado pela elite de nosso País, sob a forma de Concursos de Robustez. Nesse cenário, reformas de ordem urbana, legislativa e burocrática conduziram o País à adaptar sua estrutura fundada no oligopólio cafeeiro. Nas palavras do idealizador do referido Código:

O menor é para o Estado um valor econômico e um valor social; contribui para o desenvolvimento do povoamento, do solo e para a manutenção da integridade e da independência da Pátria; por isso, além de outras razões, a vida dos menores é preciosa à Nação. ${ }^{4}$

\footnotetext{
2 MONCORVO FILHO, Arhur. Histórico da proteção à infância no Brasil. Rio de Janeiro: Empreza Graphica Editoria, 1927. p. 34.

3 WADSWORTH, James E. Moncorvo Filho e o problema da infância. Revista Brasileira de História, São Paulo, v. 19, n. 37, set. 1999.

4 ALVARENGA NETTO. Código de Menores: doutrina, legislação e jurisprudência. Rio de Janeiro: Freitas Bastos, 1929. p. 109.
} 
Quanto à imputação da responsabilidade penal juvenil, o Código elaborado pelo Juiz de Menores José Cândido Albuquerque Mello Mattos, Decreto n. 17.943, de 1927, consignava três limites de idade: com 14 anos o infrator era inimputável; de 14 até 16 anos ainda era considerado irresponsável, mas instaurava-se um processo para apurar o fato com possibilidade de cerceamento de liberdade; finalmente, entre 16 e 18 anos, o menor poderia ser considerado responsável, sofrendo pena. Isso porque, no mesmo sentido do que apontamos acima "chegou-se à conclusão de que questões relativas à infância e à adolescência devem ser abordadas fora da perspectiva criminal, ou seja, fora do Código Penal". 5

O projeto assistencialista encabeçado por Moncorvo Filho e Mello Mattos não ficou isento de inúmeros ataques por parte da opinião pública; note-se a matéria veiculada no jornal A Manhãm citada por Veronese:" "Assistência a menores. Uma legislação que peca pela base. Impressionados pelos efeitos, esquecemo-nos do grande mal". Com isso, não se demorou que tendências conservadoras passassem a concentrar o papel de formuladores de políticas públicas infanto-juvenis. Tendo sido calcadas as bases pelo próprio Mello Mattos, a ideologia higienista ganhou força com o avançar das décadas, consolidando-se, inicialmente, com o Serviço de Assistência a Menores - SAM, Decreto-lei n. 3.779/1941, e, em 1964, com a criação da Funabem - Fundação Nacional do Bem-estar do Menor, Lei n. 4.513.

A primeira é a inauguradora da perspectiva correcionista, aplicada em suas Escolas Modelares, através da pedagogia da disciplina e do patriotismo, num momento onde o estudo da sociedade brasileira guardava interpretações evolucionistas e deterministas. A segunda, de tendência mais extremista, insere a questão no âmbito da segurança nacional, fazendo uso de recursos de prevenção e controle do problema do menor. Não é preciso dizer que a Funabem tinha como objetivo maior conter qualquer tipo de contradição entre sociedade e estado, uma vez que todas as políticas de segurança eram elaboradas por parte da Escola Superior de Guerra, responsável por atribuir à questão da infância o status de problema social. ${ }^{7}$

Por fim, a Lei Federal n. 6.697, de 1979 (Ano Internacional da Criança), o chamado Código de Menores, reafirmou mais uma vez o teor do Código Penal, de 1940, quando classificou o menor de 18 anos como absolutamente inimputável. Para dar

\footnotetext{
5 VERONESE, Josiane Rose Petry. Os direitos da criança e do adolescente. São Paulo: Editora LTr, 1999. p. 28.

6 Id. Ibid., p. 31.

7 Id. Ibid., p. 33.
} 
conta de apreender a múltipla realidade da infância e juventude brasileiras, adotou-se a casuística do Instituto Interamericano da Criança (OEA), a situação irregular, para se falar de crianças e adolescentes carentes, abandonados, desassistidos ou dados à prática de atos anti-sociais. Por melhor que pudesse ter sido a intenção do Instituto, é certo que a aplicação das categorias por ele elaboradas, a respeito da proteção da infância numa ordem social onde vigorava um regime militar, certamente, estaria fadada ao fracasso.

Não foi por outro motivo que tal legislação deu seqüência, com todo rigor, ao projeto ideológico sanitarista em curso durante a primeira metade do século XX. Rememore-se que o prudente arbitrio do juízo de menores (art. $8^{\circ}$ ) não pode ser considerado propriamente um direito do adolescente infrator. $\mathrm{Na}$ letra da lei, uma medida não precisaria atender ao critério da proporcionalidade sobre a gravidade da infração cometida, isto porque não era exigido fixação de prazo de internação (art. 41 caput), situação em que o adolescente, tendo completado 18 anos, passaria à jurisdição do juízo incumbido das Execuções Penais (art. $41 \S 3^{\circ}$ ). Também havia a possibilidade de prisão cautelar mesmo sem flagrante (art. 99 e 16), possibilidade inadmissível aos adultos. ${ }^{8}$

Ademais, entre 1979 e 1990, inúmeras outras correções seriam necessárias, até mesmo em sede constitucional, haja vista que a Constituição, de 1967, havia diminuído a idade mínima de trabalho para 12 anos, embora reconhecesse o ensino obrigatório até os 14 anos, idade esta que é a mínima permitida pela Convenção n. 138 da OIT para o trabalho infantil. De tal sorte que uma legislação autoritária aplicada no contexto de um país mais uma vez seduzido pelos planos autoritários de modernização não poderia obter êxito. Existem inúmeras razões para se perceber isso depois de 1959, quando da Declaração de Direitos da Criança (Resolução da Assembléia Geral da ONU 1.386). Indicaremos aqui seis delas.

\section{Respostas globais para um problema global}

A primeira e mais importante é resultado do VII Congresso das Nações Unidas sobre Prevenção do Delito e Tratamento do Delinqüente (1985). O informe preparado pela Secretaria-Geral nos diz que a questão dos adolescentes infratores não se resolve apenas com uma nova lei penal, pois se trata de uma realidade bastante complexa, muito relacionada com a ordem social existente, por essa razão a ação deve ser integral.

\footnotetext{
Vide EC n. 1/69. Sem dúvida, cogitamos tal argumento sem, no entanto, ignorarmos a vigência do Ato Institucional n. 5 , em especial seus arts. $4^{\circ}$ e $5^{\circ}$, sobre a cassação de direitos políticos e liberdade civil, que cessou no governo de Ernesto Geisel, exatamente em 1979.
} 
A segunda consta da conhecida Regras Mínimas das Nações Unidas para a Administração da Justiça de Menores (Regras de Beijing), também de 1985, e parte de uma sensata advertência. Embora tais normas possam parecer difíceis de aplicar, nas atuais condições sociais, econômicas, culturais, políticas e jurídicas são, contudo, consideradas como devendo constituir os objetivos mínimos da política relativa à Justiça de Menores:

\begin{abstract}
1.2. Os Estados membros esforçar-se-ão por criar condições que assegurem ao menor uma vida útil na comunidade fomentando, durante o período de vida em que o menor se encontre mais exposto a um comportamento desviante, um processo de desenvolvimento pessoal e de educação afastado tanto quanto possível de qualquer contacto com a criminalidade e a delinqüência.
\end{abstract}

A terceira delas, está contida na Convenção Americana sobre Direitos Humanos, de 1969, o conhecido Protocolo de San Salvador (art. 19), que é a convenção complementar à carta constitutiva da OEA, Organização dos Estados Americanos. Posteriormente, essa Convenção foi complementada por meio de um Protocolo Adicional (1988), de modo a reforçar as regras por ela ditadas. Vejamos o que diz este último:
Artigo 1
Obrigação de adotar medidas
Os Estados Partes neste Protocolo Adicional à Convenção
Americana sobre Direitos Humanos comprometem-se a adotar as medidas necessárias, tanto de ordem interna como por meio da cooperação entre os Estados, especialmente econômica e técnica, até o máximo dos recursos disponíveis e levando em conta seu grau de desenvolvimento, a fim de conseguir, progressivamente e de acordo com a legislação interna, a plena efetividade dos direitos reconhecidos neste Protocolo.
(...)
Artigo 16 Direito da criança
Toda criança, seja qual for sua filiação tem direito às medidas de proteção que sua condição de menor requer por parte de sua família, da sociedade e do Estado. Toda criança tem direito de crescer ao amparo e sob a responsabilidade de seus pais; salvo em circunstâncias excepcionais/ reconhecidas judicialmente, a criança de tenra idade não deve ser separada de sua mãe. Toda criança tem direito à educação gratuita e obrigatória, pelo menos no nível básico, e a continuar sua formação em níveis mais elevados do sistema educacional.

Em seguida, para o quarto argumento, temos as Regras Mínimas das Nações Unidas Para a Proteção dos Menores Privados de Liberdade, de 1990, a qual, já no preâmbulo, sustenta "preocupação com o fato de muitos sistemas não diferenciarem 
adultos e jovens nos vários estágios da administração da justiça e com o fato de os jovens serem assim detidos em prisões e outros estabelecimentos com adultos". Nas Regras, compreende-se por adolescente a pessoa entre 12 e 18 anos, sendo necessária determinação legal sobre o limite da maioridade penal. Ainda dispõe:

17. Os menores que estão detidos preventivamente ou que aguardam julgamento (não-julgados) presumem-se inocentes e serão tratados como tal. A detenção antes do julgamento deve ser evitada, na medida do possível, e limitada a circunstâncias excepcionais. Devem, por isso, ser feitos todos os esforços para se aplicarem medidas alternativas. No entanto, quando se recorrer à detenção preventiva, os tribunais de menores e os órgãos de investigação tratarão tais casos com a maior urgência, a fim de assegurar a mínima duração possível da detenção. Os detidos sem julgamento devem estar separados dos menores condenados.

18. As condições em que um menor não-julgado se encontra detido devem estar de acordo com as regras abaixo estabelecidas, sob reserva de disposições especiais, julgadas necessárias e apropriadas em razão da presunção da inocência, da duração da detenção e do estatuto legal e circunstâncias do menor. Estas disposições devem incluir, mas não necessariamente restringir-se, ao seguinte:

a) Os menores devem ter direito aos serviços de um advogado e poder requerer assistência judiciária gratuita, quando essa assistência esteja disponível, e comunicar regularmente com os seus conselheiros legais. A privacidade e confidencialidade de tais comunicações deve ser assegurada;

b) Sempre que possível, os menores devem dispor de oportunidades de efetuar um trabalho remunerado, e de continuar a sua educação e formação profissional, mas não lhes deve ser exigido que o façam. O trabalho, os estudos ou a formação profissional não devem causar a continuação da detenção;

c) Os menores podem receber e guardar materiais para os seus tempos livres e recreio, na medida em que isso for compatível com os interesses da administração da justiça."

$\mathrm{O}$ argumento de número cinco se refere ao Congresso da ONU posterior àquele de 1985, que aprova as Diretrizes para a prevenção da delinqüência juvenil, elaboradas em 1988 e cujo texto, de indispensável leitura, merece aqui a transcrição completa dos itens referentes à administração da justiça:

VI. LEGISLAÇÃO E ADMINISTRAÇÃO DA JUSTIÇA

DA INFÂNCIA E DA ADOLESCÊNCIA 
50. Os governos deverão promulgar e aplicar leis e procedimentos especiais para fomentar e proteger os direitos e o bem-estar de todos os jovens.

51. Deverá ser promulgada e aplicada uma legislação que proíba a vitimização, os maus-tratos e a exploração das crianças e dos jovens.

52. Nenhuma criança ou jovem deverá ser objeto de medidas severas ou degradantes de correção ou castigo no lar, na escola ou em qualquer outra instituição.

53. Deverão ser adotadas e aplicadas leis que regulamentem e controlem o acesso das crianças e jovens às armas de qualquer tipo.

54. Com o objetivo de impedir que se prossiga à estigmatização, à vitimização e à incriminação dos jovens, deverá ser promulgada uma legislação pela qual seja garantido que todo ato que não seja considerado um delito, nem seja punido quando cometido por um adulto, também não deverá ser considerado um delito, nem ser objeto de punição quando for cometido por um jovem.

55. Poderá ser considerada a possibilidade de se estabelecer um escritório de "proteção da infância e da adolescência" (ombudsman) ou um escritório análogo independente que garanta o respeito da condição jurídica, dos direitos e dos interesses dos jovens e, também, a possibilidade de remeter casos aos serviços disponíveis.Do mesmo modo, deverão ser estabelecidos serviços de defesa jurídica da criança.

56. O pessoal, de ambos os sexos, da polícia e de outros órgãos de justiça deverão ser capacitados para atender às necessidades especiais dos jovens; essa equipe deverá estar familiarizada com os programas e as possibilidades de remessa a outros serviços, e devem recorrer a eles sempre que possível, com o objetivo de evitar que os jovens sejam levados ao sistema de justiça penal.

57. Leis deverão ser promulgadas e aplicadas, estritamente, para proteger os jovens do uso indevido das drogas e de seus traficantes.

Portanto, fez-se necessário que crianças e adolescentes passassem a gozar de direitos, quer dizer, ter reconhecidos seus interesses, no limite da sua condição peculiar de desenvolvimento e, por fim, que os assuntos a elas concernentes devessem ser considerados prioridade absoluta na ordem social. Esses quatro pressupostos elementares, fruto da pesquisa elaborada pela Organização das Nações Unidas e da consolidação de imperativos éticos que a norteiam, foram consolidados na Convenção das Nações Unidas Sobre os Direitos das Crianças (1989). 
Assim, com este sexto item, temos o panorama completo das principais alterações que se deram no decorrer do século XX, às quais nenhum debate sobre a questão da infância e juventude pode se refutar. Do mesmo modo, a opção legislativa da Constituinte de 1988, arts. 205, 227 e 228, harmoniza-se com tais documentos internacionais. Inequívoca a regra expressa no art. 227:

É dever da família, da sociedade e do Estado assegurar à criança e ao adolescente, com absoluta prioridade, o direito à vida, à saúde, à alimentação, à educação, ao lazer, à profisssionalização, à cultura, à dignidade, ao respeito, à liberdade e à convivência familiar e comunitária, além de colocá-los a salvo de toda forma de negligência, discriminação, exploração, violência, crueldade e opressão.

A esse propósito, diz Flávia Piovesan que “o Direito Internacional dos Direitos Humanos ainda permite, em determinadas hipóteses, o preenchimento de lacunas apresentadas pelo Direito brasileiro", valendo-se da pertinente jurisprudência que cotejou o art. 233 do Estatuto da Criança e do Adolescente. Segundo alegação da defesa de policial militar acusado de praticar tortura contra crianças, o referido artigo não constituiria norma penal válida em face de seu conteúdo aberto, porque não especifica os elementos da conduta. Diante disso, houve necessidade de manifestação do $\mathrm{STF}^{9}$ para que fosse entendida a recepção automática de diplomas internacionais de proteção dos direitos humanos no plano constitucional, a suprir a alegada lacuna, como se deu com o art. $1^{\circ}$ da Convenção Contra a Tortura e Outros Tratamentos ou Penas Cruéis, Desumanos e Degradantes (1975). ${ }^{10}$

\subsection{Redução da maioridade ou redução do achismo?}

De acordo com o Estatuto da Criança e do Adolescente (ECA), o sistema de responsabilização do adolescente infrator é taxativo (em seis medidas sócio-educativas), mas pode ser aplicado em conjunto com medidas de proteção, por exemplo, determinar matrícula em escola. Essa possibilidade tem importante relevância, uma vez que 51\% desses adolescentes não se encontravam estudando quando da prática do ato infracional,

\footnotetext{
9 Cf. HC 70389-5/SP, apud PIOVESAN, Flávia. Direitos humanos e o direito internacional constitucional. São Paulo: Max Limonad, 1996. p. 117 e CURY, Munir (Coord.). Estatuto da Criança e do Adolescente Comentado. São Paulo: Malheiros, 2005. p. 769 e ss.

${ }^{10}$ PIOVESAN, Flávia. op. cit., p. 375-376.
} 
bem como porque a defasagem média de estudo entre os internos da Febem é da ordem de 5 anos. ${ }^{11}$

Possui o ECA uma doutrina especial, de vertente pedagógica, expresso no tripé políticas públicas, medidas protetivas, medidas de segurança. É sabido que o ECA é pouco cumprido nos três âmbitos, entretanto, é neste último aspecto que se repercutem maiores polêmicas. Cumpre observar, de início, os inúmeros posicionamentos da sociedade civil a respeito da aplicação das regras do Estatuto, nos quais protestam pela falta de previsão legal do direito de presença de um advogado na fase investigatória de apuração do ato infracional. Infelizmente, a situação ainda não foi revertida, pois em 2000 o então presidente Fernando Henrique Cardoso vetou o Projeto de Lei n. 24/2000 que procurava suprir tal omissão. Esquivar-se de garantia como essa equivale ao anverso de outro dado cruel: quando crianças e adolescentes são vítimas de violação de direitos. ${ }^{12}$

Para o município de São Paulo, observando homicídios praticados contra crianças e adolescentes, no ano de 1991, constatou-se que apenas 1,72\% de todos os crimes denunciados alcançaram uma sentença condenatória transitada em julgado até o final do período observado, 1994. Essa tendência parece ter-se mantido ao longo da década. Em 1999, transitaram pelo [extinto] I Tribunal de Júri da Capital cerca de 10 mil processos instaurados para apuração de responsabilidade penal em homicídios. Em torno de 70\%, os processos foram arquivados. ${ }^{13}$ Dez anos depois, as estatísticas ainda são preocupantes: 18.599 jovens entre 15 e 24 anos tiveram suas mortes provocadas por causas violentas no Brasil (duas pessoas por hora), revela pesquisa monitorada pelo Núcleo de Estudos da Violência da USP, ${ }^{14}$ que acrescenta: "a ineficácia do Estado alimenta o crime, a violência e a insegurança da população".

${ }_{11}$ Dados são informados pelo ILANUD. Disponível em <http://www.ilanud.org.br>. Acesso em: 28 maio 2007. É no mínimo curioso observar que o índice de defasagem é o mesmo apresentado pelos representantes do ILANUD na Costa Rica quando do III Seminário Latino-Americano Do Avesso ao Direito em 1992, in III SEMINÁRIO LATINO AMERICANO, São Paulo. Do avesso ao direito, da situação Irregular a proteção integral da infância e da adolescência na América Latina, Compilado por Cecília Simonetti, Margaret Blecher, Emílio Garcia Mendez, São Paulo, 1982. p. 183.

12 VERONESE, Josiane Rose Petry. Discriminação e atentados ao exercício da cidadania da criança e do adolescente. In: PEREIRA, Tânia da Silva (Coord.). O melhor interesse da criança: um debate interdisciplinar. Rio de Janeiro: Renovar, 1999. p. 653-695.

13 CASTRO, Myriam Mesquita Pugliese de. Vidas sem valor: um estudo sobre os homicídios de crianças e adolescentes e a atuação das instituições de segurança e justiça. Originalmente apresentado como Tese de Doutorado em Sociologia. 1996, PPGS/FFLCH -USP.

14 Núcleo de Estudos da Violência, Universidade de São Paulo. Terceiro Relatório Nacional Sobre os Direitos Humanos no Brasil. São Paulo: NEV-USP, 2002-2005. Disponível em: <http://www.nevusp.org/conteudo/ index.php?conteudo_id=609>. Acesso em: 28 maio 2007. 
Ainda, segundo Juarez Cirino, ${ }^{15}$ "o sistema de controle social atua sobre jovens socialmente prejudicados e deficitários, mas, em especial, sobre os segmentos mais prejudicados e mais deficitários da juventude”. O melhor exemplo, diz o Autor, são os registros policiais que mostram que adolescentes primários comparados a adolescentes reincidentes têm escolarização superior (77\% contra 56\%); com maior freqüência possuem profissão (58\% contra 37\%); e exercem emprego (35\% contra 12\%). Isto demonstra, que variáveis como escolarização deficiente e desemprego explicam, em parte, as distorções.

O IBGE aponta quase 25 milhões de adolescentes no Brasil, sendo que o número deles vivendo sob regime de internação é da ordem de 16 mil (sim, 0,0006\% do total!), número ínfimo, portanto, com tendência à redução caso houvesse reconhecimento judicial de que parcela significativa dos internos poderia cumprir a medida em liberdade (art. 122 do ECA). Do total de internos, 76\% estão entre 16 e 18 anos, fato que justificaria à opinião conservadora a redução da maioridade penal. Contudo, esses setores da sociedade (que hoje se expressam na opinião de $47 \%$ dos parlamentares, segundo pesquisa recente da Fundação Getúlio Vargas - FGV publicada pelo jornal O Estado de S. Paulo ${ }^{16}$ ) não se atentam para um dado elementar: tal faixa etária representa o período de maior vulnerabilidade do desenvolvimento humano.

Argumentam, talvez por amor à retórica, que se ao adolescente de 16 anos é reconhecido o direito político de ir às urnas, também o deve arcar responsabilizando-se criminalmente. Um dado objetivo ajuda a refutar o argumento: não mais que dois milhões de jovens entre 16 e 17 anos exercem tal prerrogativa $(0,08 \%$ da população nessa faixa etária). Da mesma forma esquecem-se que com a redução da maioridade penal outros direitos podem passar a ser exigíveis, tal como a carteira de habilitação (que é responsável por índices elevados de mortes violentas); ao passo que certos direitos podem ser restritos, tal como o atendimento prioritário no sistema de saúde (art. 11 do ECA).

Isto posto, é imperativo reconhecer que, de modo geral, os jovens ainda compõem um setor vitimizado, e não-agressor, no panorama da violência criminal, numa trajetória de omissões do poder público que persiste até mesmo depois de aplicadas medidas de internação. Em relatório de pesquisa realizada pelo IPEA consta que $71 \%$ dos estabelecimentos de internação não atendem pedagogicamente às necessidades especiais devidas, e que 94\% deles faz uso do sistema público de saúde, o qual notoriamente é reconhecido pela péssima qualidade em nosso País.

\footnotetext{
15 SANTOS, Juarez Cirino. O adolescente infrator e os direitos humanos. Capturado no site do professor da UFPR. Disponível em: <http://www.cirino.com.br>. Acesso em: 28 maio 2007.

16 Notícia em circulação no dia 21.05.2007.
} 
Ainda, o Ilanud e o Unicef elaboraram um minucioso estudo, referente a todos os Estados brasileiros, que serve de guia prático e teórico à aplicação das medidas sócio-educativas, e nesse sentido coaduna-se com o recém implantado Sinase - Sistema Nacional de Atendimento Sócio-Educativo, que visa obter cooperação entre os três níveis de governo no monitoramento das medidas sócio-educativas aplicadas. Isto porque, como aponta o relatório Ilanud/Unicef, a maior parte dos Estados sequer apresenta diretrizes que orienta a execução das medidas (por exemplo, na Região Sudeste nenhum dos Estados as elaborou). Também estão ausentes programas de geração de renda e de apoio ao egresso.

De forma ampla, entendem educadores e profissionais comprometidos com a proteção da infância e da juventude que todas as atividades, bem como os relacionamentos que são travados com o adolescente, devem confluir para a finalidade educativa à qual se propõe a medida, e só o farão se puderem contemplar as demandas dos sujeitos atendidos. Junto aos adolescentes, faz-se necessário considerar as significações atribuídas à vinculação e à desvinculação com a prática infracional, considerando os movimentos que permitem, na vida de cada um, a existência de novas e velhas possibilidades de dar prosseguimento às suas trajetórias. Estar atento aos rearranjos dinâmicos,${ }^{17}$ aos quais as trajetórias de vida são submetidas, rearranjos estes que contribuem para a descontinuidade na prática infracional e para a construção de novos sentidos de si, pode constituir um caminho que ofereça perspectivas de saída antes impensadas em políticas e ações de reinserção social.

\subsection{Mordendo o próprio rabo}

A propósito do debate em torno da redução da maioridade penal, são dois os possíveis caminhos radicais: reduzir ou-não. Um deles é de caráter simplista e empiricamente inseguro: aquele que pretende maior rigor para o controle da criminalidade por intermédio da redução da maioridade penal. Contudo, pelo que foi exposto acima, seria não-só ilegal diante do ordenamento internacional como ineficaz defender tal medida. Existem diversos estudos ainda a serem realizados, por parte de inúmeras instituições de pesquisas e organizações internacionais, governamentais ou-não, com o que somente diante de projeções eficazes e legitimamente respaldadas pelo sistema de direitos humanos é que poderia ser aplicada a diminuição da maioridade.

De antemão, os defensores de tal recurso precisam reconhecer que nenhum resultado global será atingido sem que se sigam as receitas já oferecidas pela doutrina da

${ }_{17}$ COSTA, Cláudia Regina Brandão Sampaio Fernandes da. É possível construir novos caminhos? Da necessidade de ampliação do olhar na busca de experiências bem-sucedidas no contexto sócio-educativo. Revista Estudos e Pesquisas em Psicologia, Rio de Janeiro, ano 5, n. 2, 2005. 
proteção integral. Isto porque ela ultrapassa a compreensão imediatista do problema e aponta para estratégias coordenadas de solução do impasse. Estas, com muito pesar, não chegam a tempo, haja vista a implementação do Sinase ter-se dado tão-somente em 2007. Da mesma forma lamentável o Governo brasileiro ter cumprido com exagerado atraso, tão-somente em 2004, a exigência do art. 44 da Convenção de 1990 . $^{18}$

De modo geral, é possível afirmar que não há correlação necessária entre a aplicação de medidas mais severas e a diminuição da criminalidade. Admitimos, apenas por argumentação, o estudo The Rest of Their Lives: Life without Parole for Child Offenders in the United States, elaborado pela Human Rights Watch y Amnistía Internacional (12 de outubro de 2005, disponível em http://www.es.amnesty.org). Isto porque, vale lembrar, os Estados Unidos não são signatários da Convenção de 1990 e mantém 2.225 pessoas cumprindo pena perpétua sem liberdade provisória devido a delitos cometidos, quando menores de 18 anos. Ainda assim, nos valeremos dele pela clareza solar com a qual expõe os fatos:

No hay correlación entre el uso de la cadena perpetua sin liberad condicional y los índices de delincuencia juvenil. No hay indicios de que esta pena impida la delincuencia juvenil o sirva para reducir sus índices. Por ejemplo, en Georgia raras veces se condena a menores a cadena perpetua sin libertad condicional, pero los índices de delincuencia juvenil en este estado son menores que en Misuri, donde se impone la pena a menores con mucha más frecuencia.

Ademais, tais argumentos consistem na desconstrução do sistema de garantias fundamentais da pessoa humana por meio da promoção de uma lógica perversa, segundo a qual mesmo a diminuição da criminalidade resultará em punição mais severa dos adolescentes infratores:

Aunque se ha reducido el número de menores que cometen delitos graves, como asesinato, los estados los condenan cada vez más a cadena perpetua sin libertad condicional. En 1990, por ejemplo, fueron declarados culpables de asesinato 2.234 menores, y al 2,9 por ciento de ellos se los condenó a cadena perpetua sin libertad condicional. En 2000, el índice de sentencias condenatorias se había reducido casi un 55 por ciento (1.006), pero el porcentaje de menores condenados a cadena perpetua sin libertad condicional ascendió un 216 por ciento ( a 9 por ciento).

\footnotetext{
${ }_{18}$ Disponível em: $<$ http://www.mj.gov.br/sedh/ct/discursos/duscurso\%20nilmario\%20onu\%20crianca.doc>.
} 
No mesmo sentido, submetidos ao sistema penitenciário adulto, onde $70 \%$ da população carcerária tem entre 18 e 27 anos de idade, no caso brasileiro, diminuiriam ainda mais as possibilidades de reinserção social do adolescente, uma vez que nas unidades de internação o índice de reincidência atinge 30\%, ao passo que no sistema aplicado aos adultos ultrapassa $70 \%$.

\section{Conclusão}

Diante de tudo o que foi exposto, o que aproxima e ao mesmo tempo repele a aceitação da diminuição da maioridade penal como instrumento necessário ao controle de criminalidade, parece ser uma mesma idéia: prioridade, urgência, necessidade. Contudo, em uma das alternativas essa idéia se encontra fora do lugar adequado. A questão da infância e da juventude em nenhuma das esferas de governo (federal, estaduais ou municipais) foi encarada como prioridade social na história política do Brasil.

Alocar esse reclame de urgência em medidas criminais, sem bases empíricas precisas e com referencial ético, mais uma vez termina por demonstrar a mesma falta de prioridade, num círculo vicioso que insiste no autoritarismo já empreendido no seio das legislações "menoristas", de 1927 e de 1979, que não deve se repetir nos dias de hoje. Ao contrário, urgência é necessária para a aplicação de outras medidas. Não é de se ignorar que a medida sócio-educativa de internação esteja alocada como recurso de ultima ratio, senão incorreria na penalização de situações sociais que deveriam ser motivo de atenção comunitária e estatal, não-judiciária.

Afinal, efetivar as diretrizes do Estatuto será providência de grande valor. Basta lembrar que somente 20\% das Delegacias Especializadas foram implantadas; apenas 34\% das Defensorias Públicas; e Conselhos Municipais dos Direitos da Criança e do Adolescente ainda faltam em $21 \%$ dos municípios. Outro problema indubitável é o das Varas Especializadas da Infância e Juventude, as quais muitas vezes, sob esse nome, também compartilham processos criminais, da vara da família, comercial, etc.

Os dados mostram que a maioria dos adolescentes internos vivia com a família, inclusive porque em $62,77 \%$ das ocorrências registradas em delegacias da cidade de São Paulo, os adolescentes estavam na presença de seus familiares. ${ }^{19}$ Portanto, investir em ações e programas que fortaleçam os vínculos familiares mantidos pelos adolescentes pode reduzir as chances de entrada no mundo da delinqüência juvenil. Da mesma forma, é

19 Dados apresentados por SPOSATO, Karyna. O direito penal juvenil no Estatuto da Criança e do Adolescente. 2003. Dissertação (Mestrado) - Faculdade de Direito, Universidade de São Paulo, São Paulo. p. 136. 
oportuno que as políticas de garantia de direitos, especificamente as políticas públicas, de modo geral, sejam direcionadas à família e não ao adolescente de forma isolada, como se daria com a diminuição da maioridade penal.

Há, portanto, muitíssimas possibilidades a serem discutidas. E todas elas antecedem a medida de diminuição da maioridade penal, pois não padecem do vício do oportunismo, que vem sempre acompanhado do autoritarismo. Indicamos algumas, a título de exemplo, colhidas entre estudos do Grupo de Trabalho ${ }^{20}$ sobre as propostas de redução da maioridade penal, procedidas na Comissão Temporária Especial do Congresso Nacional, ou outras oferecidas por estudiosos, advertindo que merecem análise cuidadosa antes de serem aplicadas.

Igualmente, promover ações que contribuam não apenas para ampliar a escolarização dos jovens entre 12 e 18 anos de idade como, também, concorram para diminuir a evasão destes meninos das escolas, pois os dados mostraram que freqüentar as escolas diminui as chances de internação. Ações de profissionalização com vistas a ampliar as oportunidades no mercado de trabalho também oferecem resultados positivos, uma vez que muitos jovens internados não trabalhavam quando cometeram o delito que os conduziu à internação.

A associação do uso de drogas à violência juvenil também é outra realidade mostrada por pesquisas. Assim, investir em ações massivas de prevenção ao uso de drogas pode reduzir a violência entre os adolescentes. O ECA prevê o tratamento de saúde específico gratuito à criança e ao adolescente usuários de drogas. Desse modo, seria muito importante que a sociedade e governos canalizassem esforços para a materialização desse preceito do ECA.

É necessário que os adolescentes privados de liberdade não sejam submetidos a sanções adicionais que os privem de seus direitos fundamentais. Para isso, é preciso que os olhares se voltem não apenas para essa parcela dos jovens brasileiros, mas também para as políticas chamadas "universais", bem como para ações específicas que garantam o verdadeiro direcionamento para a sua reinserção social. De modo suplementar poderia haver precisão de que os antecedentes criminais dos autores de atos infracionais ficassem disponíveis para os juízes e promotores criminais, quando voltarem a transgredir a lei após atingirem a maioridade penal.

Por outro lado, já se reconheceu a necessidade do aumento do período de internação nos casos de criminalidade violenta e reiteração de atos infracionais, a fim de

${ }^{20}$ Cf. <http://www2.camara.gov.br/comissoes/temporarias/grupos/gtcrianc/reunioes.html>. 
atender à proporcionalidade entre a conduta, a reprimenda e o tratamento sócio-educativo, e no mesmo sentido promover a rigorosa separação entre os autores de atos infracionais com as seguintes faixas etárias: até 15 anos; de 15 a 18 anos, e os maiores de 18 anos que ainda estejam cumprindo medida sócio-educativa.

Um aspecto de melhora seria a previsão de obrigatória separação também para os infratores considerados psicopatas ou portadores de graves desvios de personalidade, considerados de difícil ou impossível recuperação, a serem avaliados periodicamente, por equipe multidisciplinar (não se trata, aqui, de adotar o critério biopsicológico, mas de individualizar apenas a execução do tratamento e da reprimenda àqueles que colocam em risco a recuperação dos demais), e até previsão de medida de segurança no âmbito do Estatuto da Criança e do Adolescente, inclusive com a especificação do local adequado para o seu cumprimento (hospital de custódia e psiquiátrico) e da avaliação periódica por equipe multidisciplinar. ${ }^{21}$

Erigir à condição de crime autônomo a ação do adulto que é mandante ou partícipe de crime em concurso com menor de 18 anos, e estabelecer uma rigorosa agravação da pena cominada ao crime praticado em concurso foi a opção que sensibilizou o deputado federal Aloísio Mercadante, ${ }^{22}$ em fevereiro deste ano. Nos casos em que a criança ou adolescente sofrer lesão corporal grave no momento do crime, a pena do adulto aumenta em um terço e, se houver morte, a pena é duplicada.

Por fim, o Projeto de Lei de Execução das Medidas Sócio-Educativas, a ser apresentado este mês pelo presidente Luis Inácio Lula da Silva ao Congresso, também pode apontar para soluções mais articuladas (via Sinase), respaldadas democraticamente. $\mathrm{O}$ custo social de iniciativas assim certamente será bastante menor que promover a inserção de número maior de jovens em penitenciárias. E que com isso se promovam pesquisas que registrem sua aplicação no decorrer do tempo, cruzando-se os resultados com informações tais como a que recentemente foi divulgada pelo portal eletrônico de informações da Secretaria de Estado da Justiça do Governo do Estado de São Paulo.

Em anúncio no portal eletrônico da Secretaria, no ano de 2006, pela primeira vez, o número de internações na extinta Febem foi menor que o número de

${ }^{21}$ CAVALLIERI, Alyrio. Falhas no Estatuto da Criança e do Adolescente. Rio de Janeiro: Forense, 1995. p. 55; e também os psiquiatras: AMARO, Jorge Wohney Ferreira. O debate sobre a maioridade penal. Revista de Psiquiatria Clínica, v. 31, n. 3, p. 142-144, 2004; KAUFMANN, Arthur, Maioridade penal. Revista de Psiquiatria Clínica, v. 31, n. 3, p. 105-106, 2004 e o estudo _. Personalidade psicopática em uma amostra de adolescentes infratores brasileiros. Revista de Psiquiatria Clínica, v. 36, n. 6, p. 297-303, 2006.

${ }^{22}$ Projeto de Lei 118/03, aprovado pela CCJ do Senado Federal. 
desinternações. ${ }^{23}$ Estas, por sua vez, já expressavam aumento (19,6\% entre 2004 e 2006), o que pode se intensificar com a aplicação efetiva dos instrumentos previstos pelo ECA, sobretudo aqueles dispostos no Livro II, Títulos I e II. Resta esclarecer em pesquisas futuras, com instrumentais metodológicos sérios, e não meramente opinativos, os motivos de tal redução.

Em vista dos problemas analisados, ousamos dizer que quase todas as propostas aqui sugeridas remontam senão à provocação de tornar efetivo o Estatuto da Criança e do Adolescente através do que ele já prevê. Tais propostas foram sintetizadas não porque, entendemos, se tratar de problemas pontuais, mas, muito pelo contrário, porque se reconhece a necessidade de promoção de debates públicos, direcionados por pesquisas contextualizadas à realidade da infância e juventude, nos quais a participação dos atores da rede de proteção é indispensável.

São Paulo, dezembro de 2007.

\section{Referências}

AMARO, Jorge Wohney Ferreira. O debate sobre a maioridade penal. Revista de Psiquiatria Clínica, n. 31 (3), p. 142-144, 2004.

CAVALliERI, Alyrio. Falhas no Estatuto da Criança e do Adolescente. Rio de Janeiro: Forense, 1995.

CASTRO, Myriam Mesquita Pugliese de. Vidas sem valor: um estudo sobre os homicídios de crianças e adolescentes e a atuação das instituições de segurança e justiça. Originalmente apresentado como Tese de Doutorado em Sociologia, PPGS/FFLCH -USP. 1996.

COSTA, Cláudia Regina Brandão Sampaio Fernandes da. É possível construir novos caminhos? Da necessidade de ampliação do olhar na busca de experiências bem-sucedidas no contexto sócioeducativo. Revista Estudos e Pesquisas em Psicologia, Rio de Janeiro, ano 5, n. 2, 2005.

COSTA, Ana Paula Motta. As garantias processuais do direito penal juvenil. Porto Alegre: Livraria do Advogado, 2005.

CURY, Munir (Coord.). Estatuto da Criança e do Adolescente Comentado. São Paulo: Malheiros, 2005.

\footnotetext{
${ }_{23}$ Disponível em: $<$ http://www.justica.sp.gov.br/Noticia.asp?Noticia=2814>. Acesso em: 28 maio 2007.
} 
KAUFMANN, Arthur, Maioridade Penal. Revista de Psiquiatria Clínica, v. 31, n. 3, p. 105-106, 2004.

. Personalidade psicopática em uma amostra de adolescentes infratores brasileiros. Revista de Psiquiatria Clínica, v. 36, n. 6, p. 297-303, 2006.

KOSMINSKY, Ethel Volfzon. Internados - filhos do Estado padrasto. In: MARTINS, José de Souza. Massacre dos inocentes. São Paulo: Hucitec, 1993.

MONCORVO FILHO, Arhur. Histórico da proteção à infância no Brasil. Rio de Janeiro: Empreza Graphica Editoria, 1927.

NÚCLEO DE ESTUDOS DA VIOLÊNCIA. Universidade de São Paulo. Terceiro relatório nacional sobre os direitos humanos no Brasil. São Paulo: NEV-USP, 2002-2005, disponível em: <http://www. nevusp.org/conteudo/index.php?conteudo_id=609>. Acesso em: 28 maio 2007.

PIOVESAN, Flávia. Direitos humanos e o direito internacional constitucional. São Paulo: Max Limonad, 1996.

ROSA, Alexandre Morais da. Introdução crítica ao ato infracional. Rio de Janeiro: Lúmen Juris, 2007.

SANTOS, Juarez Cirino. O adolescente infrator e os direitos humanos. Disponível em: < http:// www.cirino.com.br>. Acesso em: 28 maio 2007.

Seminário Latino-Americano Do Avesso ao Direito em 1992. In: III SEMINÁRIO LATINO AMERICANO. Do avesso ao direito, da situação irregular a proteção integral da infância e da adolescência na América Latina. Compilado por Cecília Simonetti, Margaret Blecher, Emílio Garcia Mendez. São Paulo, 1982.

SPOSATO, Karyna. O direito penal juvenil no Estatuto da Criança e do Adolescente. 2003. Dissertação (Mestrado) - Faculdade de Direito, Universidade de São Paulo, São Paulo.

VERONESE, Josiane Rose Petry. Os direitos da criança e do adolescente. São Paulo: Editora LTr, 1999.

. Discriminação e atentados ao exercício da cidadania da criança e do adolescente. In: PEREIRA, Tânia da Silva (Coord.). O melhor interesse da criança: um debate interdisciplinar. Rio de Janeiro: Renovar, 1999

WADSWORTH, James E. Moncorvo Filho e o problema da infância. Revista Brasileira de História, São Paulo, v. 19, n. 37, set. 1999. 